\title{
Biological Treatment of Concentrated Hazardous, Toxic, and Radionuclide Mixed Wastes Without Dilution
}

William T. Stringfellow ${ }^{1}$, Tatsuyuki Komada ${ }^{1}$, and Li-Yang Chang ${ }^{2}$

${ }^{1}$ Center for Environmental Biotechnology

Earth Sciences Division

${ }^{2}$ Environmental Health and Safety Division

Lawrence Berkeley National Laboratory

Berkeley, California

Corresponding Author:

William T. Stringfellow

Mail Stop 70A-3317

Center for Environmental Biotechnology

Lawrence Berkeley National Laboratory

Berkeley, California 94720

Phone: (510) 486-7903

Fax: (510) 486-7152

e-mail: wstringfellow@lbl.gov 


\begin{abstract}
Approximately $10 \%$ of all radioactive wastes produced in the U. S. are mixed with hazardous or toxic chemicals and therefore can not be placed in secure land disposal facilities. Mixed wastes containing hazardous organic chemicals are often incinerated, but volatile radioactive elements are released directly into the biosphere. Some mixed wastes do not currently have any identified disposal option and are stored locally awaiting new developments. Biological treatment has been proposed as a potentially safer alternative to incineration for the treatment of hazardous organic mixed wastes, since biological treatment would not release volatile radioisotopes and the residual low-level radioactive waste would no longer be restricted from land disposal. Prior studies have shown that toxicity associated with acetonitrile is a significant limiting factor for the application of biotreatment to mixed wastes and excessive dilution was required to avoid inhibition of biological treatment. In this study, we demonstrate that a novel reactor configuration, where the concentrated toxic waste is drip-fed into a complete-mix bioreactor containing a pre-concentrated active microbial population, can be used to treat a surrogate acetonitrile mixed waste stream without excessive dilution. Using a drip-feed bioreactor, we were able to treat a 90,000 mg/L acetonitrile solution to less than $0.1 \mathrm{mg} / \mathrm{L}$ final concentration using a dilution factor of only 3.4. It was determined that the acetonitrile degradation reaction was inhibited at a $\mathrm{pH}$ above 7.2 and that the reactor could be modeled using conventional kinetic and mass balance approaches. Using a drip-feed reactor configuration addresses a major limiting factor (toxic inhibition) for the biological treatment of toxic, hazardous, or radioactive mixed wastes and suggests that drip-feed bioreactors could be used to treat other concentrated toxic waste streams, such as chemical warfare materiel.
\end{abstract}




\section{Introduction}

Approximately ten percent of all radioactive waste produced in the United States is mixed with hazardous waste and therefore can not be sent to licensed radioactive waste, land disposal facilities until it is treated to meet Resource Conservation and Recovery Act (RCRA) land disposal restrictions (NRC 2001, DOE 2000, Waters and Gruebel 1997). The land disposal restriction for many non-chlorinated organic solvents, including acetonitrile, can be $1.0 \mathrm{mg} / \mathrm{L}$ or less (USEPA 2003). Radioactive wastes are classified as mixed wastes if they contain characteristic or listed hazardous waste under RCRA and are classified as “low-level” wastes under Nuclear Regulatory Commission classifications (Waters and Gruebel 1997, NRC 2001). The RCRA hazardous waste list includes both organic and inorganic chemicals. The U. S. Department of Energy (DOE) does not track RCRA listed organic and inorganic wastes separately, but DOE is the largest producer of mixed waste in the U. S. (DOE 2000). A 1997 study identified $130,000 \mathrm{~m}^{3}$ of mixed waste awaiting treatment or disposal at DOE Facilities (Waters and Gruebel 1997). Estimates of commercial sector mixed waste generation are as high as $140,000 \mathrm{~m}^{3}$ per year (NRC 2001, USEPA/NRC 1992). Mixed wastes represent 5 to $10 \%$ of all radioactive waste produced in the biomedical and academic communities and $70 \%$ of these mixed wastes are RCRA listed based on their hazardous organic content (NRC 2001).

Mixed wastes containing RCRA hazardous organic waste, such as waste oil, scintillation fluid, and spent chromatography solvents, are typically treated of by incineration (NRC 2001, DOE 2000, Ismagilov et al. 2000, Schwinkendorf et al. 1995). Incineration destroys the hazardous organic component of the mixed waste and the radioactive component is captured with the fly-ash or released with stack gasses (Birk 1998, Ismagilov et al. 2000, Martin and Manahan 1998, Tries et al. 1996, Hochel 1997). Less volatile radionuclides are collected with 
the fly-ash and can be sent to land disposal facilities so long as they meet the permissible radionuclide concentration and were not over-concentrated during incineration (Birk 1998, Waters and Gruebel 1997). Tritium (hydrogen-3), carbon-14, and iodine-125 are essentially 100\% volatilized during incineration and released with stack gasses (Tries et al. 1996, Hochel 1997). Release of radioactive materials during incineration poses a challenge for facilities attempting to meet zero discharge goals and for facilities producing mixed wastes with high specific radioactivity (Chang et al 1999, Hageman 2002, Waters and Gruebel 1997). Radioactive waste incineration facilities are designed by volume capacity and charge by volume of material, but, mixed waste incinerators have limits on the total radioactivity they can release per year and add surcharges based on waste radioactivity (NRC 2001). Consequently, incineration costs can be very high even for small volumes of waste (Tries et al. 1996, NRC 2000, Hageman 2002, Chang et al. 1999). For example, costs for commercial incineration of tritiated mixed waste from the National Tritium Labeling Facility (NTLF) was estimated to be as much as $\$ 200,000,000$ (Chang et al. 1999). If the waste were no longer hazardous, land disposal costs of low level wastes are estimated to be approximately $\$ 330,000$ at commercial facilities (NRC 2001) or less at DOE disposal sites.

For mixed wastes where incineration is unavailable or cost prohibitive or land disposal is restricted, there may be no identified legal disposal options (Hageman 2002, Waters and Gruebel 1997, Chang et al. 1999, Schwinkendorf et al. 1995). These “orphan” mixed wastes are typically not generated in large volumes, but significant innovation is needed to resolve individual mixed waste disposal challenges (Hageman 2002, Waters and Gruebel 1997). In a recent survey of DOE facilities, approximately $5,100 \mathrm{~m}^{3}$ of mixed wastes were classified as having characteristics that prevent them from being sent to existing DOE or commercial 
radioactive waste disposal facilities (DOE 2000). The median volume associated with an individual orphan waste was only $3 \mathrm{~m}^{3}$ and one third of the orphan mixed wastes were produced in a volume of one $\mathrm{m}^{3}$ or less. Orphan mixed wastes are also generated in the biomedical and academic sectors (NRC 2001, Hageman 2002).

Most studies examining alternative treatment processes have not addressed treatment issues specific to volatile radioisotopes (Schwinkendorf et al. 1995, Ismagilov et al. 2000, Martin and Manahan 1998, Wolfram et al. 1997, Vanderberg et al. 1999, Chang et al. 1999). It has been proposed that biological treatment could present an alternative to incineration for the treatment of mixed wastes containing biodegradable organic solvents (Hageman 2002, Wolfram et al. 1997, Schwinkendorf et al. 1995, Chang et al. 2002). Biological treatment offers potential advantage in that it is a low-temperature treatment that can be done in "units" of tanks or containers and is therefore allowable for on-site treatment under the U. S. Environmental Protection Agency (USEPA) final mixed waste rule (USEPA 2001, Hageman 2002). Additionally, biological treatment can be completely contained in a variety of ways (most commonly in completely sealed reactors such as respirometers), so that no waste is released into the biosphere until treatment is determined to be adequate. In contrast, loss of process control during thermal treatment results in an immediate release of radioactive or hazardous materials to the atmosphere (Birk 1998).

Vanderberg et al. (1999) described a combined physical and biological treatment procedure for treating paint and solvent wastes produced during decontamination and decommissioning of nuclear weapon complexes. To avoid toxicity to the biological treatment system, volatile organic solvents were separated from non-volatile radioactive metals (plutonium and americium) by air-stripping before biotreatment. Air stripping was also used in other studies 
to circumvent substrate inhibition effects in biological reactors treating mixed wastes containing xylenes (Wolfram et al. 1997). Air stripping may be appropriate for some orphan mixed wastes, but air-stripping tritiated wastes increases the probability tritium will escape to the atmosphere during treatment. Additionally, air stripping is inefficient for removing high solubility, low volatility solvents such as acetonitrile and methanol.

Avoiding substrate inhibition is the most significant challenge in designing biological treatment systems for concentrated or toxic wastes (Lee et al. 1996, Wolfram et al. 1997, Vanderberg et al. 1999, Chang et al. 2002, Schwinkendorf et al. 1995, Shem et al. 1996). Studies examining the treatment of inhibitory wastes typically utilize or evaluate continuous stirtank reactors (CSTRs) or a variety of batch reactor configurations (Lee et al. 1996, Wolfram et al. 1997, Vanderberg et al. 1999, Schwinkendorf et al. 1995, Shem et al. 1995). Substrate inhibition of treatment is commonly avoided by diluting a toxic waste to a concentration below the corresponding half-saturation constant $\left(\mathrm{K}_{\mathrm{s}}\right)$ or some reference concentration known to be non-toxic (Lee et al. 1996, Wolfram et al. 1997). For highly toxic wastes, such as chemical warfare materiel (CWM), dilution is not inherently undesirable, except that dilution may require increased handling and thereby increase chance of human or environmental exposure (NRC 2000, NRC 2002). Increasing flow volume by dilution will also require a larger reactor for equivalent treatment. In the case of mixed wastes, dilution is undesirable because disposal costs for radioactive wastes are based on volume as well as radioactivity. Using biological treatment to remove the hazardous component of the mixed waste to meet land disposal restrictions is not practical if the volume of the waste is increased to the point that land disposal costs become prohibitive. 
Wolfram and collaborators demonstrated that bacteria could be used to degrade common solvent constituents of mixed wastes, including methanol and acetonitrile (Wolfram et al. 1997). However, most solvents found in mixed wastes were inhibitory to bacterial activity and required dilution before treatment. Acetonitrile was noted as being particularly toxic to bacteria and was not degraded at a $0.1 \%(\mathrm{v} / \mathrm{v})$ concentration. Partial treatment of acetonitrile was achieved at concentrations of $0.04 \%$ or less. Complete treatment could only be achieved at higher initial biomass concentrations and lower initial acetonitrile concentrations (Wolfram et al. 1997). A typical tritiated mixed waste generated from a chromatographic process can contain $10 \%$ or greater acetonitrile (Chang et al. 1999, Chang et al. 2002) and would require extensive dilution to be treated using typical batch or CSTR biological treatment systems.

In this study, we tested the hypothesis that a drip-feed, batch-treatment bioreactor could be used to treat mixed wastes under contained conditions with minimal dilution. We tested the drip-feed bioreactor against a surrogate of an acetonitrile mixed waste produced during the purification of tritium labeled biomedical research reagents at the NTLF (Chang et al 1999, Chang et al. 2002). Using a drip-feed bioreactor configuration, we were able to treat a $10 \%$ acetonitrile solution to a final concentration of less than $0.1 \mathrm{mg} / \mathrm{L}$ with a final dilution factor of only 3.4. The results of this research demonstrate that biological treatment is a viable alternative for the treatment of concentrated toxic, hazardous, or mixed wastes.

\section{Materials and Methods}

Bacterial inoculum. An acetonitrile degrading culture was enriched from an uncontaminated soil collected in Berkeley, CA. Two grams of this soil was added to $50 \mathrm{~mL}$ deionized water in a flask and was shaken for two hours. One $\mathrm{mL}$ of liquid phase from the soil extract was transferred into a $500 \mathrm{~mL}$ Erlenmeyer flask containing $200 \mathrm{~mL}$ single source carbon 
(SSC) media supplemented with $0.5 \mathrm{~mL}$ acetonitrile. The volume of this culture was increased to $300 \mathrm{~mL}$ during subsequent transfers. The culture was maintained by drawing and discarding $200 \mathrm{~mL}$ of the culture each week, and by replacing the discarded volume with $200 \mathrm{~mL}$ of SSC and $0.5 \mathrm{~mL}$ acetonitrile.

SSC medium consists of $1000 \mathrm{mg} / \mathrm{L} \mathrm{KH}_{2} \mathrm{PO}_{4}, 860 \mathrm{mg} / \mathrm{L} \mathrm{Na}_{2} \mathrm{HPO}_{4}, 1000 \mathrm{mg} / \mathrm{L} \mathrm{NH} \mathrm{Cl}_{4}$, $120 \mathrm{mg} / \mathrm{L} \mathrm{MgSO}_{4}, 60 \mathrm{mg} / \mathrm{L} \mathrm{CaCl}_{2}$, and $1 \mathrm{~mL} / \mathrm{L}$ of trace metal solution. Nitrogen Free Minimal Media (NFMM) was the same as SSC media, but without $\mathrm{NH}_{4} \mathrm{Cl}$. The trace metal solution was composed of $3.3 \mathrm{mg} / \mathrm{L} \mathrm{MnSO}{ }_{4}-\mathrm{H}_{2} \mathrm{O}, 6.2 \mathrm{mg} / \mathrm{L} \mathrm{CuSO}_{4}-5 \mathrm{H}_{2} \mathrm{O}, 7.6 \mathrm{mg} / \mathrm{L} \mathrm{ZnSO}{ }_{4}-7 \mathrm{H}_{2} \mathrm{O}, 11.7 \mathrm{mg} / \mathrm{L}$ $\mathrm{Na}_{2} \mathrm{MoO}_{4}-2 \mathrm{H}_{2} \mathrm{O}, 64.6 \mathrm{mg} / \mathrm{L} \mathrm{FeSO}{ }_{4}-7 \mathrm{H}_{2} \mathrm{O}$, and $4.15 \mathrm{~mL} \mathrm{HCl}$ in one liter distilled-deionized water.

The bacterial culture used to prepare the initial reactor biomass was grown by inoculating $10 \mathrm{~mL}$ of the acetonitrile enrichment culture into two one-liter batches of NFMM supplemented with acetonitrile to maintain an acetonitrile concentration of between 100 and $200 \mathrm{mg} / \mathrm{L}$. After 17 days of growth under theses conditions, $200 \mathrm{~mL}$ of NFMM was added to both cultures to make up the total volume of 1.2 liters per culture. $300 \mathrm{~mL}$ draw-fill maintenance was done on these cultures every four days.

The acetonitrile enrichment culture was washed three times with NFMM before being inoculated into the reactor. The washing was done by centrifuging the enrichment culture (total volume of 2.4 liters) with Beckman J2-HS centrifuge at 8000 rpm for 10 minutes per wash. The culture pellet was resuspended in $100 \mathrm{~mL}$ of NFMM and used to inoculate the drip-feed reactor.

Batch growth kinetics. Bacterial growth kinetics were measured using $250 \mathrm{~mL}$ side arm flasks containing $50 \mathrm{~mL}$ of SSC media containing acetonitrile at concentrations ranging from 40 $\mathrm{mg} / \mathrm{L}$ to $100,000 \mathrm{mg} / \mathrm{L}$ at $25^{\circ} \mathrm{C}$. Flasks were inoculated with $0.1 \mathrm{~mL}$ of a washed acetonitrile 
enrichment culture and tightly sealed with screw-caps. The initial optical density of each flask was recorded and then the flasks were placed on an orbital shaker ( 250 rpm's at $25^{\circ} \mathrm{C}$ ). Optical density measurements were taken approximately every half hour during log growth stage. Growth rates $(\mu)$ for each concentration of acetonitrile was obtained by graphing the natural log of the optical density as a function of time. Acetonitrile was an inhibitory substrate and biokinetic parameters for growth were estimated using the Haldane model for inhibitory substrates:

$$
\mu=\mu_{\max } \mathrm{S}\left(\mathrm{K}_{\mathrm{m}}+\mathrm{S}+\mathrm{S}^{2} \mathrm{~K}_{\mathrm{i}}^{-1}\right)^{-1}
$$

Where, $\mu$ is the observed growth rate, $\mu_{\max }$ is the maximum growth rate, $\mathrm{S}$ is the substrate (acetonitrile) concentration, $\mathrm{K}_{\mathrm{m}}$ is the half-saturation constant, and $\mathrm{K}_{\mathrm{i}}$ is the inhibitory substrate concentration. Biokinetic estimates were obtained from the model fit using nonlinear regression.

Oxidation kinetics. Acetonitrile culture from the draw-fill reactor were harvested, washed three times and resuspended in SSC media and the optical density was measured. The respirometer (Clark type electrode) was calibrated with distilled water saturated with oxygen. All experiments were conducted at $25^{\circ} \mathrm{C}$. Approximately $1.7 \mathrm{~mL}$ of the acetonitrile culture was then placed into the respirometer. The oxygen uptake of the culture was monitored for approximately ten minutes, until a steady baseline was recorded. Solutions of acetonitrile in distilled water were prepared to give final concentrations ranging from $10 \mathrm{mg} / \mathrm{L}$ to $10,000 \mathrm{mg} / \mathrm{L}$ in the respirometry cell. Ten $\mu \mathrm{L}$ of the acetonitrile solution was injected into the cell and the oxygen uptake rate was measured. Net oxygen uptake rates were determined by subtracting the baseline oxygen uptake rate from the rate after the injection of substrate and results were corrected for biomass concentration (specific oxygen uptake rate) as previously described (Stringfellow and Aitken 1995). Then the oxygen uptake rate as a function of acetonitrile 
concentration was fit with the Michaelis-Menten model to estimate the kinetic parameters $\mathrm{K}_{\mathrm{m}}$ and SOUR $\max$ (the maximum specific oxidation rate).

Acetonitrile oxidation kinetics were examined at concentrations well below the $\mathrm{K}_{\mathrm{i}}$, so the Michaelis-Menten model was used to estimate biokinetic constants:

$$
v=\mathrm{V}_{\max } \mathrm{S}\left(\mathrm{K}_{\mathrm{m}}+\mathrm{S}\right)^{-1} \quad \text { [eq. 2] }
$$

Where, $v$ is the observed oxidation rate, $\mathrm{V}_{\max }$ is the maximum oxidation rate, $\mathrm{S}$ is the substrate (acetonitrile) concentration, and $\mathrm{K}_{\mathrm{m}}$ is the half-saturation constant. Biokinetic estimates were obtained from the model fit using nonlinear regression.

Drip-feed bioreactor. Treatment experiments were conducted using a Bioflo 3000 bioreactor (New Brunswick Scientific). For initial conditions, the reactor was filled with 1.9 liters of NFMM and then inoculated with $100 \mathrm{~mL}$ of washed culture. Pure oxygen was used to aerate the reactor at an initial flow of between 4 and $5 \mathrm{~mL} / \mathrm{min}$ and an agitation speed of 150 rpm. The temperature of the reactor was maintained at $25^{\circ} \mathrm{C}$. A $10 \%$ acetonitrile influent was fed to the reactor with Ismatec IPC (16-channel, 8-roller) tubing pump at the rates ranging between two and six mL/day using Masterflex Norprene Food tubing, size L/S 16 (Cole-Parmer Instruments, Vernon Hills, IL). The 10\% acetonitrile influent was prepared by diluting HPLC grade acetonitrile into Millipore water in a 1-L volumetric flask. The acetonitrile was purchased from EM Science.

The flow was commenced immediately after the enrichment culture inoculation. The initial influent flow was set to $4 \mathrm{~mL} /$ day. At different times, the flow rate was varied between 2, 4, and $6 \mathrm{~mL}$ per day. The actual flow rate was measured by weighing the influent bottle at each sampling time. 
Biological growth in the drip-feed reactor were modeled using a basic mass balance:

$$
\mathrm{X}_{\mathrm{t} 2}=\mathrm{X}_{\mathrm{t} 1}+\mathrm{YM}_{\mathrm{t}}-\mathrm{k}_{\mathrm{d}}\left(\mathrm{t}_{2}-\mathrm{t}_{1}\right) \mathrm{X}_{\mathrm{t} 1}
$$

Where $\mathrm{X}_{\mathrm{t} 2}$ is biomass at time $\mathrm{t}_{2}, \mathrm{X}_{\mathrm{t} 1}$ is biomass at time $\mathrm{t}_{1}, \mathrm{Y}$ is the apparent bacterial growth yield, $\mathrm{M}_{\mathrm{t}}$ is the mass of acetonitrile biotreated in time $\left(\mathrm{t}_{2}-\mathrm{t}_{1}\right)$, and $\mathrm{k}_{\mathrm{d}}$ is the decay constant.

Sampling. Samples were collected in order to conduct optical density, ammonia, nitrate, and acetonitrile analyses. Samples were drawn out from a sampling port with a 10-mL disposable glass pipette. NFMM was added after each sampling so that the volume in the reactor was kept constant at two liters. For example, if $10 \mathrm{~mL}$ had been drawn out from the reactor and $4 \mathrm{~mL}$ of influent had gone into the reactor since the last sampling, $6 \mathrm{~mL}$ of NFMM would be added back to the reactor for that sampling. At each sampling, the reactor operating conditions—reactor temperature, jacket chiller temperature, condenser chiller temperature, agitation speed, $\mathrm{pH}$, dissolved oxygen (DO), and oxygen flow were recorded.

Biomass and ammonia analysis. Bacterial biomass concentration was measured by reading absorbance at $590 \mathrm{~nm}$ on Hach DR/2000 Direct Reading Spectrophotometer or a Perkin Elmer UV/VIS Spectrometer Lambda 20 (double-beam). Absorbance was converted to biomass using a standard relationship developed for each instrument. Ammonia was analyzed using diluted samples by the Hach Nessler Method 8038 (Hach 1997).

Acetonitrile analysis. Acetonitrile was quantified using a HP6890 gas chromatograph (Aglient) fitted with a flame ionization detector (GC-FID). Five $\mathrm{mL}$ of reactor sample was first dispensed into a 13-mm culture tube and acidified by adding two drops of $6 \mathrm{~N} \mathrm{HCl}$ solution. The acidified culture was dispensed into a centrifuge tube and the sample was centrifuged at a speed 
of $9100 \mathrm{rpm}$ for 3.5 minutes. The supernatant phase was collected and triplicate samples were analyzed. Separation was achieved using a DB-624 capillary column (J\&W, 30.0 m X $250 \mu \mathrm{m}$ $\mathrm{X} 1.40 \mu \mathrm{m}$ nominal), with an initial oven temperature of $140^{\circ} \mathrm{C}$ for 4 minutes followed by a $16^{\circ}$ C per minute temperature increase to $150^{\circ} \mathrm{C}$, which was held for 2 minutes. The inlet and detector temperatures were $225^{\circ}$ and $250^{\circ} \mathrm{C}$, respectively. An auto-injector was used to inject $0.2 \mu \mathrm{L}$ of sample, the split ratio was $5.4: 1$ with helium as a carrier gas at $0.7 \mathrm{~mL} / \mathrm{min}$ flow giving an average velocity of $20 \mathrm{~cm} / \mathrm{sec}$. The FID conditions were hydrogen $40 \mathrm{~mL} / \mathrm{min}$, air 450 $\mathrm{mL} / \mathrm{min}$, and nitrogen as the make-up gas at $45 \mathrm{~mL} / \mathrm{minute}$.

\section{Results and Discussion}

\section{Determination of biokinetic limitations for solvent treatment.}

Experiments were conducted to determine kinetic limitations on the biotreatment of acetonitrile. Mixed cultures that could grow on acetonitrile as a sole carbon and nitrogen source were enriched from uncontaminated surface soils (Chang et al. 2002). Batch growth kinetics were measured at concentrations as high as 100,000 mg/L acetonitrile. Although observed even at 100,000 mg/L, growth was inhibited at high concentrations (Figure 1). Microscopic examination showed irregular shaped cells at the highest concentrations (compared to predominately small rods at lower concentrations) and apparent growth yield (Y) declined at acetonitrile concentrations above 1,000 mg/L (Figure 2). These results indicate that the culture was stressed at high acetonitrile concentrations.

The $\mathrm{K}_{\mathrm{m}}$ for acetonitrile was estimated to be $89 \mathrm{mg} / \mathrm{L}$ (Figure 3), which is high in comparison to other solvents found in mixed wastes, such as methanol, which had a measured $\mathrm{K}_{\mathrm{m}}$ of $0.2 \mathrm{mg} / \mathrm{L}$ (Chang et al. 2002) and methyl ethyl ketone which has a $\mathrm{K}_{\mathrm{m}}$ of $0.3 \mathrm{mg} / \mathrm{L}$ (unpublished data) by the same technique. Similarly, unfavorable biodegradation kinetics for 
acetonitrile have been observed with other bacterial cultures (Nawaz et al. 1989, Wolfram et al. 1997). In agreement with the conclusions of Wolfram et al. (1997), the combination of substrate inhibition and inefficient biodegradation kinetics suggest that acetonitrile will be one of the more difficult to treat of the common mixed-waste solvents.

\section{Drip-feed bioreactor conceptual design.}

The results of the initial biokinetic studies indicated that acetonitrile concentrations should be kept below 1,000 $\mathrm{mg} / \mathrm{L}$ to maintain stable performance in a biological reactor. If a $10 \%$ solution of acetonitrile was to be batch treated in a completely stirred tank reactor (CSTR), it would need to be diluted approximately one part to 100 to meet this criteria. In a flow-through or draw-fill CSTR, the tolerance for the influent acetonitrile concentration is theoretically higher (due to instantaneous reaction in the CSTR), but experience demonstrates that biological systems treating high influent concentrations of inhibitory wastes have a number of operational problems, including loss of biomass and other upset conditions, that are due at least in part to the fact that mixing is not truly ideal. Mixed wastes containing acetonitrile have been diluted and treated in previous studies (Wolfram et al. 1997), but dilution is undesirable for tritiated wastes that need to be solidified for land disposal.

To address the limitations of batch and flow-through CSTR treatment systems for treating mixed wastes, the concept of a drip-feed bioreactor was developed (Figure 4). In the drip-feed reactor, a high concentration of active biomass is prepared and placed in a reactor which is partially filled with a buffered medium. The undiluted waste is slowly fed to the active biomass at a rate sufficient to maintain activity, but low enough so that bacterial degradation maintains the aqueous concentration below the $\mathrm{K}_{\mathrm{m}}$ or some other desired concentration threshold. The reactor has no effluent, but rather fills as the undiluted waste is fed to the reactor. When the 
reactor is full, the reaction is allowed to go to completion (in the case of acetonitrile biodegradation to a concentration of less than $1.0 \mathrm{mg} / \mathrm{L}$ ), the radioactive residual is solidified and sent for land disposal. For a 10 liter batch of an orphan waste a dilution of up to 20 times would be acceptable, as targeted land disposal facilities have a minimum charge for containers less than $0.2 \mathrm{~m}^{3}$

\section{Drip-feed bioreactor operation}

For the first weeks of operation, the reactor performed as expected. Acetonitrile degradation was rapid and the acetonitrile concentration in the reactor remained below $60 \mathrm{mg} / \mathrm{L}$. Biomass and ammonia concentrations increased in the reactor. About day 13, the acetonitrile concentration in the reactor began to rise and the ammonia concentration began to plateau, indicating that the biodegradation reaction was inhibited. Acetonitrile feed was stopped on day 20 and operational parameters were evaluated to determine the cause of the inhibition.

Acetonitrile concentration was approximately $260 \mathrm{mg} / \mathrm{L}$, still well below the inhibitory concentrations as defined by our initial biokinetic studies (Figures A and C). Ammonia concentration was $800 \mathrm{mg} / \mathrm{L}$, which although high, is below concentrations typically used in medium for the cultivation of these and other similar bacteria (Chang et al. 2002, Stringfellow and Aitken 1995, Stringfellow and Oh 2002). The pH was 7.6, which is within the range considered normal for bacterial growth and still well below the $\mathrm{pK}_{\mathrm{a}}$ for ammonia, further indicating that ammonium toxicity was an unlikely cause of the observed inhibition. Trace mineral limitation was considered and on day 47 one $\mathrm{mL}$ of a trace mineral solution (see methods for composition) was added, to no effect.

On day 54, we adjusted the $\mathrm{pH}$ downward from $7.8 \mathrm{pH}$ to $7.1 \mathrm{pH}$ (Figure 5). The biodegradation reaction immediately began again and acetonitrile concentration fell to less than 
$8.0 \mathrm{mg} / \mathrm{L}$ within 10 days. The sensitivity of the acetonitrile biodegradation reaction to $\mathrm{pH}$ was unexpected. Comparison of reaction rate to $\mathrm{pH}$ demonstrates a precipitous decline in reaction rate when $\mathrm{pH}$ is above 7.2 (Figure 6). The degradation of acetonitrile to ammonia and acetic acid is catalyzed by a two-enzyme system consisting of a nitrile hydratase and an amidase (Nawaz et al. 1989, Langdahl et al. 1996, Kobayashi et al. 1996, Acharya and Desai 1997, Acharya and Desai 1999). From our results, it is apparent that this reaction requires a free $\mathrm{H}^{+}$, and that when the concentration of $\mathrm{H}^{+}$falls below $10^{-7.2} \mathrm{M}$, the reaction rate slows significantly. The precipitous sensitivity of acetonitrile biodegradation to $\mathrm{pH}$ has not been previously described. For the rest of the experiment, the reactor $\mathrm{pH}$ was kept below $\mathrm{pH} 7.2$ by the periodic addition of hydrochloric acid.

Figure 7 shows the comparison between the theoretical and actual acetonitrile concentrations in the reactor for the full duration of the experiment. The theoretical concentration is the calculated acetonitrile concentration in the reactor if there were no treatment. Overall treatment efficiency by this standard is greater than $99.999 \%$, equivalent to treatment standards for competing technologies (Schwinkendorf et al. 1995).

The drip-feed bioreactor performance could be analyzed using mass balance approaches applicable to other types of bioreactors (Stringfellow and Oh 2002). Biodegradation rate was proportional to mass loading rate (Figure 8), but at high mass loading, efficiency declined (Figure 9) and the concentration of acetonitrile in the bioreactor would increase. Biomass growth in the reactor could be described by a simple growth model (equation 3) using a Y of 0.13 mass biomass (mass acetonitrile) ${ }^{-1}$ and a $k_{d}$ of 0.0085 day $^{-1}$ (Figure 10). The apparent $\mathrm{Y}$ estimated for the drip-feed bioreactor (Figure 10) was less than that observed in the batch reaction experiments (Figure 2). Batch reaction yield measurement, made under more favorable 
growth conditions than the Drip-feed reactor experiments, are better measurement of the "true" bacteria growth yield for thermodynamic calculation.

Volatile loss of acetonitrile from the reactor was estimated to be $0.04 \%$ of the total acetonitrile treated, based on measurements of effluent gas condensates. Volatile loss was prevented by the use of a $-5^{\circ} \mathrm{C}$ condenser on the gas outlet of the reactor. Very low temperature condensers, designed specifically for trapping tritiated water, could be added to insure complete containment of the reactor (Chang et al. 1999). The fact that the loss of reaction efficiency for 35 days could be managed without the release of hazardous materials to the environment is in contrast to results from high temperature treatment, where the loss of treatment efficiency, even momentarily, can result in the immediate release of hazardous or toxic substances to the biosphere (Tries et al. 1996, Schwinkendorf et al. 1995, Shem et al. 1995).

On day 187, the acetonitrile feed was terminated and the reaction was allowed to go to completion. Acetonitrile concentration went from approximately $750 \mathrm{mg} / \mathrm{L}$ to less than 1.0 $\mathrm{mg} / \mathrm{L}$, the target concentration for land disposal, within 40 days. The final concentration of acetonitrile was less than $0.1 \mathrm{mg} / \mathrm{L}$, which is significantly lower than the land disposal restriction standard (USEPA 2003). The overall performance measures for the reactor are presented in Table 1.

The results of this research demonstrate that a drip-feed bioreactor can be used to treat solvents found in mixed wastes in a completely contained fashion, even during periods of plant upset. The main objective, treatment of the acetonitrile from $100,000 \mathrm{mg} / \mathrm{L}$ to less than 1.0 $\mathrm{mg} / \mathrm{L}$, was achieved with a dilution factor of only 3.4. The residual material had reached the RCRA land disposal restriction standard, and thus could be disposed of in a landfill. The dripfeed configuration meets the requirements for "units" of tanks or containers and is therefore 
allowable for on-site treatment under the EPA's final mixed waste rule (USEPA 2001, Hageman 2002).

It was found in this study that the acetonitrile degradation reaction was $\mathrm{pH}$ sensitive, where the optimal $\mathrm{pH}$ range for the biodegradation process was approximately between 6.5 and 7.1. Above $\mathrm{pH} 7.5$ the reaction was severely inhibited. The physiological reason for this inhibition is believed to be the need for free hydrogen ions in the reaction catalyzed by a nitrile hydratase and amidase enzyme system.

The results with acetonitrile, a toxic compound with poor biokinetic properties, further suggest that drip-feed biotreatment would offer a safe alternative for the treatment of other highly toxic, but biodegradable substances, such as sarin, VX, and mustard (Kilbane and Jackowski 1996, Lee et al. 1996, Shem et al. 1995). Challenges facing the safe disposal of chemical warfare materiel (CWM) is similar to the challenges facing the safe disposal of mixed wastes. Incineration of CWM has faced strong public opposition and there is interest in developing alternative methods for CWM treatment (NRC 2002, NRC 2000). In many cases, CWM and associated waste streams are found in small quantities at dispersed locations and it is preferable to treat the waste on-site, rather than ship CWM to central locations (NRC 2002). Biological treatment of mustard and mustard hydrolysis products have been demonstrated (Kilbane and Jackowski 1996, Lee et al. 1996, NRC 2000, NRC 2002, Shem et al. 1995), but projects examining the biological treatment of nerve agents have failed due to poor bioreactor design (NRC 2000). Novel reactor configurations, such as the drip-feed bioreactor, could offer practical alternatives to the disposal of difficult to handle waste streams. 


\section{References}

Acharya, A. and A. J. Desai. 1997, Studies on utilization of acetonitrile by Rhodococcus erythropolis A10, World J. Microbiol. Biotechnol. 13: 175 - 178.

Acharya, A. and A. J. Desai, 1999. Short communication: Acetonitrile-hydrolyzing enzymes in Rhodococcus erythropolis A10, World J. Microbiol. Biotechnol. 15: 123 - 125.

Birk, M. B. 1998. Trial burn activities for a mixed waste incinerator. Waste Management, 18: $467-471$.

Chang, L.- Y., A. Proctor, and W. T. Stringfellow. 2002. Kinetic Parameters for the Biological Treatment of Mixed Wastes Containing Acetonitrile and Methanol. Ernest Orlando Lawrence Berkeley National Laboratory Formal Report No. LBID-2433. Berkeley National Laboratory, Berkeley, CA.

Chang, L.-Y., C. Than, H. Morimoto, and P. G. Williams. 1999 (August). A Catalytic Oxidation Study and Regulatory Analysis of Tritiated Mixed Wastes. LBNL-42849. Lawrence Berkeley National Laboratory, Berkeley, CA.

Hach Company. 1997. Water Analysis Handbook, $3^{\text {rd }}$ Edition, Hach Company, Loveland, CO.

Hageman, J. P. 2002. Handling, storage, treatment, and disposal of mixed wastes at medical facilities and academic institutions. Radiation Safety Journal, 82:2: S66 - S76.

Hochel, R. C. 1997 (March). A Strategy for Quantifying Radioactive Material in a Low-Level Waste Incineration Facility. WSRC-TR-97-0106. Westinghouse Savannah River Company, Savannah River Technology Center, Analytical Development Section, Aitken, SC. 
Ismagilov, Z. R., M. A. Kerzhentsev, R. A. Shkrabina, et al. 2000. A role of catalysis for the destruction of waste from the nuclear industry. Catalysis Today, 55: $23-43$.

Kilbane, J. J. and K. Jackowski. 1996. Biocatalytic detoxification of 2-chloroethyl ethyl sulfide. J. Chem. Technol. Biotechnol. 65:370 - 374.

Kobayashi, M., T. Fujita, and S. Shimizu, 1996, Hyperinduction of nitrile hydratase acting on indole-3-acetonitrile in Agrobacterium tumefaciens, Appl. Mirobiol. Biotechnol., 45: 176 $-18$.

Langdahl, B. R., P. Bisp, and K. Ingvorsen, 1996, Nitrile hydrolysis by Rhodococcus erythropolis BL1, an acetonitrile-tolerant strain isolated from a marine sediment, Microbiology 142: 145 - 154 .

Lee, T.-S., M. Q. Pham, W. W. Weigand, S. P. Harvey, and W. E. Bentley. 1996. Bioreactors strategies for the treatment of growth-inhibitory waste: an analysis of thiodiglycol degradation, the main hydrolysis product of sulfur mustard. Biotechnology Progress, 12: $533-539$.

Martin, R. S. and S.E. Manahan. 1998. Fate of radioactive arsenic, cesium, strontium, and organo-chlorine during the gasification of mixed wastes in the presence of organic matter. Chemosphere, 37:3: $531-540$.

National Research Council (NRC). 2000. Evaluation of Demonstration Test results of Alternative Technologies for Demilitarization of Assembled Chemical Weapons - A Supplemental Review. National Academy Press, Washington, DC. 
National Research Council (NRC). 2001. The Impact of Low-Level Radioactive Waste Management Policy on Biomedical Research in the United States. National Academy Press, Washington, DC.

National Research Council (NRC). 2002. Systems and Technologies for the Treatment of NonStockpile Chemical Warfare Materiel. National Academy Press, Washington, DC.

Nawaz, M. S., K. D. Chapatwala, and J. H. Wolfram, 1989, Degradation of Acetonitrile by Pseudomonas putida, Appl. Environ. Microbiol., 55:2267 - 2274.

Schwinkendorf, W. E., J. McFee, M. Devarakonda, L. L. Nenninger, F. S. Fadullon, T. L. Donaldson, and K. Dickerson. 1995 (April). Alternatives to Incineration Technical Area Status Report. DOE/MWIP-26. Mixed Waste Integrated Program, U. S. Department of Energy, office of Technology Development, Washington, DC.

Shem, L. M., D. H. Rosenblatt, M. P. Smits, P. L. Wilkey, S. W. Ballou, and M. G. Besmer. 1995 (December). Preliminary Screening of Alternative Technologies to Incineration for Treatment of Chemical-Agent-Contaminated Soil, Rocky Mountain Arsenal. ANL/ESD32. Argonne National Laboratory, Argonne, IL.

Stringfellow, W. T. and K. -C. Oh. 2002. Initiation of methyl tert-butyl ether biotreatment in fluidized-bed bioreactors. J. Environ. Eng. 128 (9): 852 - 861.

Stringfellow, W. T. and M. D. Aitken. 1995. Competitive metabolism of naphthalene, methylnaphthalenes, and fluorene by phenanthrene degrading bacteria. Appl. Environ. Microbiol. 61:357-362. 
Tries, M. A., J.P. Ring, and G. E. Chabot. 1996. Environmental monitoring for a low-level radioactive waste management facility-incineration operations. Health Physics 71(3): $384-394$.

U. S. Department of Energy (DOE). 2000. The Current and Planned Low-Level Waste Disposal Capacity Report, Revision 2. December. Us. Department of Energy, Office of Environmental Management, Washington, DC.

U. S. Environmental Protection Agency and Nuclear Regulatory Commission (USEPA/NRC). 1992. National Profile on Commercially Generated Low-Level Radioactive Mixed Waste. Oak Ridge National Laboratory. NUREG/CR-5938, ORNL-6731. US Nuclear Regulatory Commission, Washington, DC.

U. S. Environmental Protection Agency (USEPA). 2003. Land Disposal Restrictions. 40 CFR Part 268, July 1, Federal Register, National Archives and Record Administration, Washington, DC.

U. S. Environmental Protection Agency. 2001. Storage, Treatment, Transportation, and Disposal of Mixed Wastes; Final Rule. 40 CFR Part 266, May 16, Federal Register, National Archives and Record Administration, Washington, DC.

Vanderberg, L. A., T. M. Foreman, M., Attrep, J. R. Brainard, and N. Sauer. N. 1999. Treatment of heterogeneous mixed wastes: Enzyme degradation of cellulosic materials contaminated with hazardous organics and toxic and radioactive metals. Environ. Sci. Technol. 33(8): 1256-1262.

Waters, R. D. and M. M. Gruebel. 1997. Volumetric and radiological capacity requirements for disposal of treated mixed low-level waste. Waste Management, 17:4: 237 - 248. 
Wolfram, J. H., M. Radtke, J. E. Wey, R. D. Rodgers, and E. H. Rau. 1997. Degradation of hazardous chemicals in liquid radioactive wastes from biomedical research using a mixed microbial population. Technology Journal of the Franklin Institute, 334A: 171 - 184. 
Table 1: Overall operational performance for the drip-feed bioreactor treating a 10\% solution of acetonitrile.

\begin{tabular}{|c|c|c|c|}
\hline Parameter & Mean & Minimum & Maximum \\
\hline Influent Acetonitrile $\left(\mathrm{mg} \mathrm{L}^{-1}\right)$ & 87,811 & 75,700 & 103,065 \\
\hline Reactor Ammonia-N (mg L $\left.{ }^{-1}\right)$ & 2,261 & 16.2 & 6,050 \\
\hline Reactor Biomass (mg L ${ }^{-1}$ ) & 1,045 & 230 & 2,346 \\
\hline Reactor Acetonitrile (mg L ${ }^{-1}$ ) & 103 & $<0.1$ & 746 \\
\hline $\begin{array}{l}\text { Loading rate } \\
\text { (mg-acetonitrile mg-biomass }^{-1} \text { ) }\end{array}$ & 0.14 & 0.0 & 0.83 \\
\hline Solids retention time (days) & 172 & 57 & 200 \\
\hline Apparent $\mu\left(\right.$ day $\left.^{-1}\right)$ & 0.01 & -0.11 & 0.24 \\
\hline 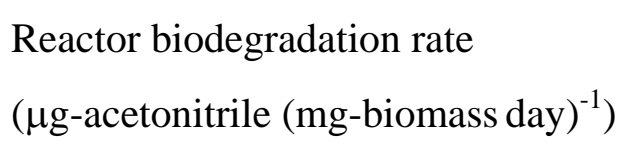 & 131 & -20 & 630 \\
\hline $\begin{array}{l}\text { Reactor oxygen uptake rate } \\
\text { (mg-oxygen (g-biomass hour) }{ }^{-1} \text { ) }\end{array}$ & 1.4 & 0.0 & 8.5 \\
\hline Influent flow (mL day ${ }^{-1}$ ) & 2.85 & 0.00 & 6.08 \\
\hline $\mathrm{pH}$ & 6.94 & 5.08 & 7.85 \\
\hline Reactor DO (\% saturation) & 87 & 56 & 115 \\
\hline Reactor Temperature $\left({ }^{\circ} \mathrm{C}\right)$ & 25 & 25 & 28 \\
\hline Condenser Temperature ( ${ }^{\circ} \mathrm{C}$ ) & -5.0 & -14 & 23 \\
\hline
\end{tabular}


Figure 1: Biokinetics of bacterial growth on acetonitrile. Bacterial growth was inhibited at high concentrations and growth kinetics could be described using a Haldane model (eq. 1, line in figure). Insert shows enlargement of results for concentrations less than $800 \mathrm{mg} / \mathrm{L}$, with same model fit.

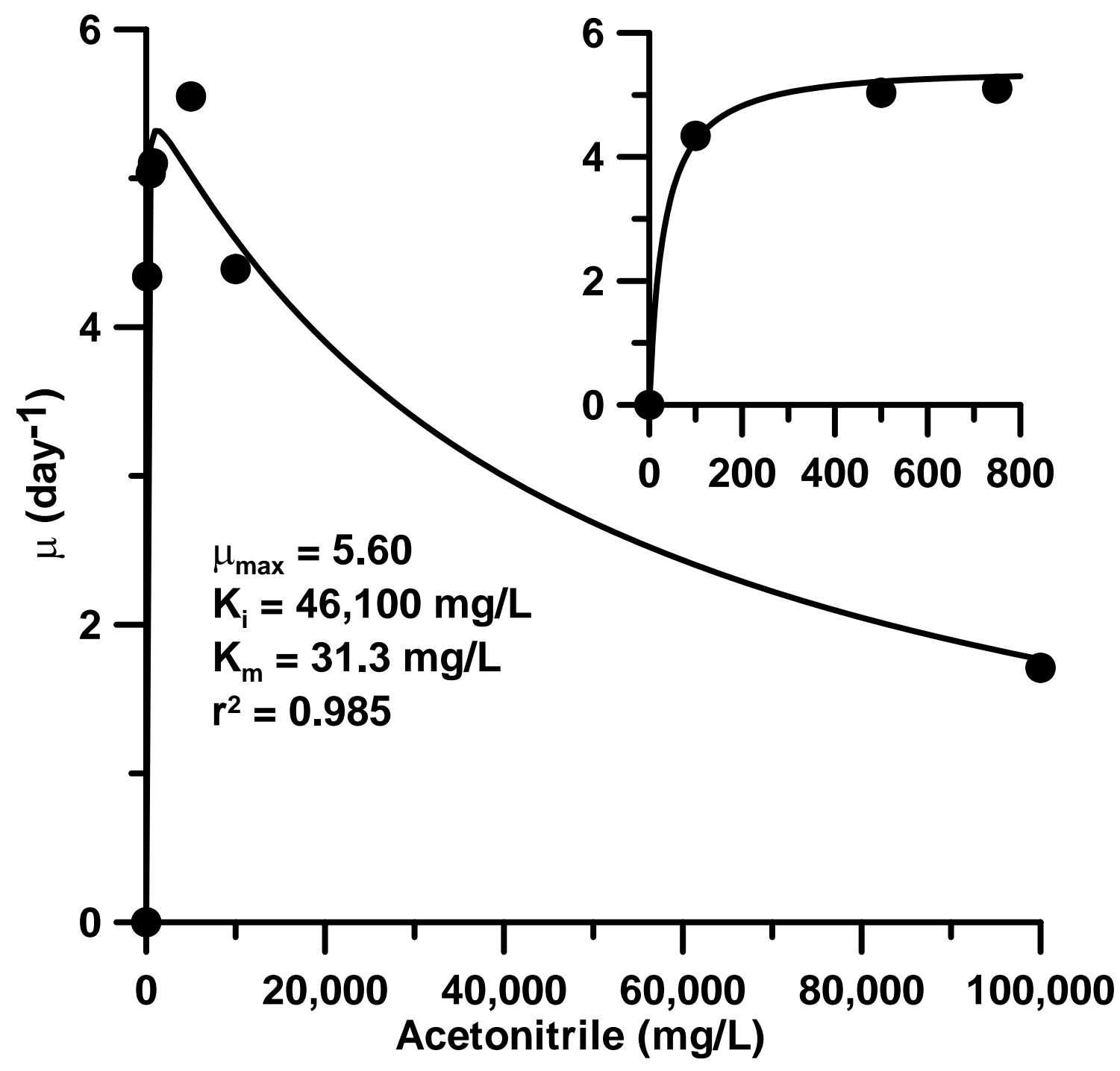


Figure 2: Bacterial growth yield (Y) on acetonitrile. Apparent growth yield declines when the bacterial mixed culture is grown at initial acetonitrile concentrations greater than $1,000 \mathrm{mg} / \mathrm{L}$. Decline in growth yield indicates culture is stressed at higher initial acetonitrile concentrations.

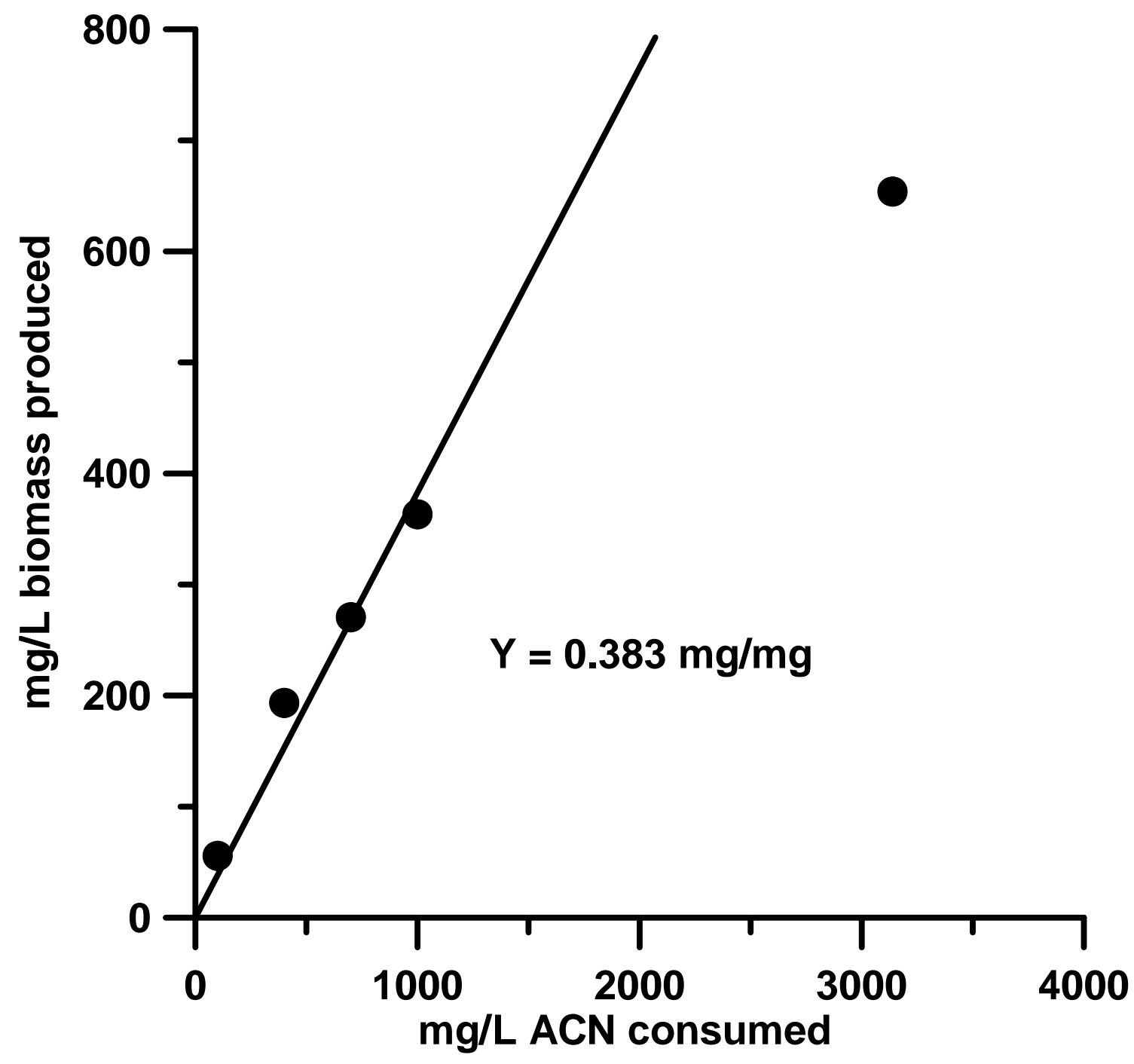


Figure 3: Biokinetics of acetonitrile oxidation by bacteria. Bacterial oxidation of acetonitrile as a function of concentration can be described using the Michaelis-Menten model (eq. 2, line in figure) at concentrations less than $10,000 \mathrm{mg} / \mathrm{L}$. Insert shows enlargement of results for concentrations less than $800 \mathrm{mg} / \mathrm{L}$, with same model fit.

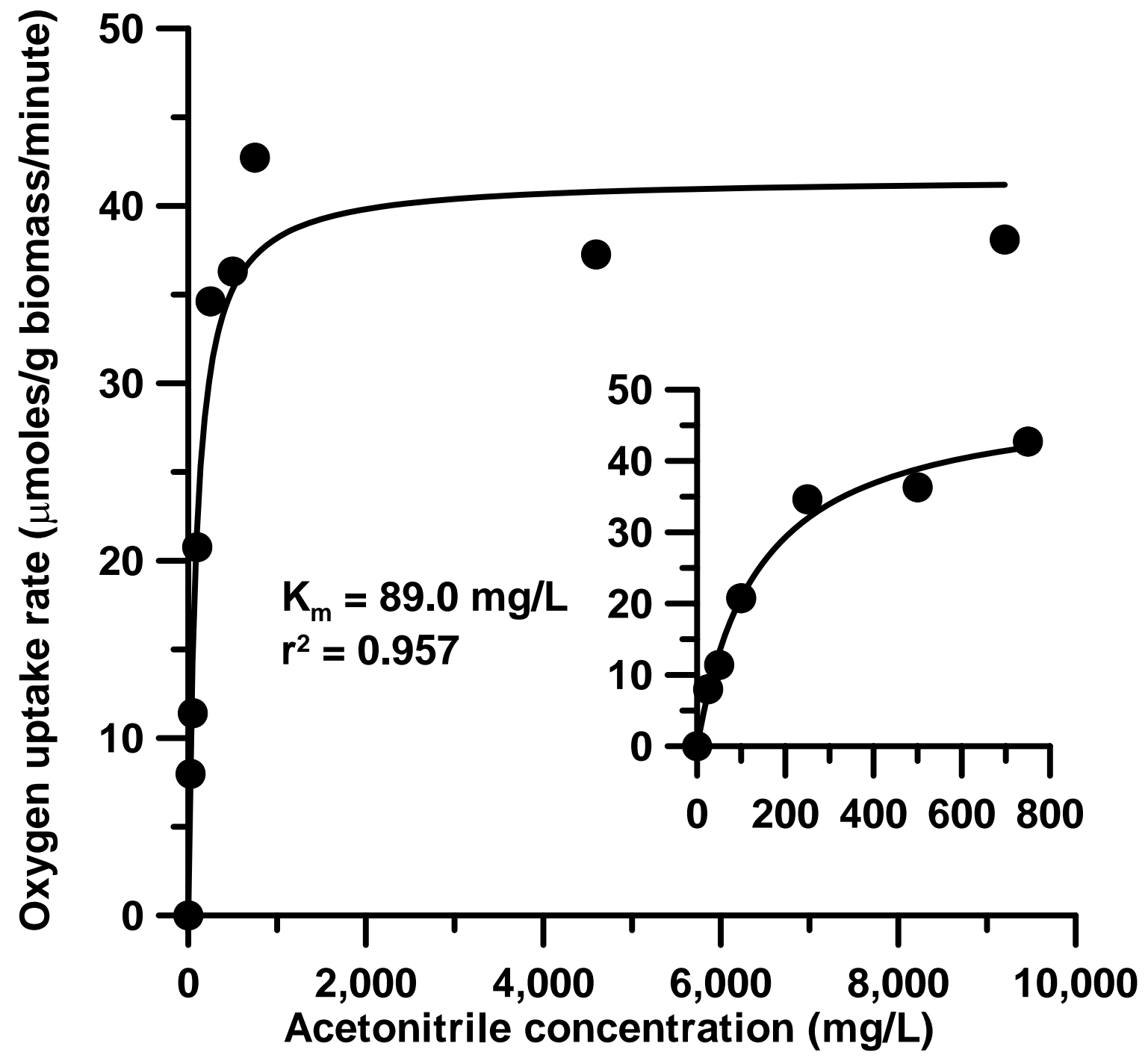


Figure 4: Schematic of a drip-feed bioreactor. Concentrated toxic waste is fed slowly into the bioreactor which contains a concentrated, active microbial biomass in a buffered medium. As the reactor fills the toxic waste is degraded. The use of pure oxygen and a low temperature condenser minimizes volatile loss of radioactive or toxic wastes.

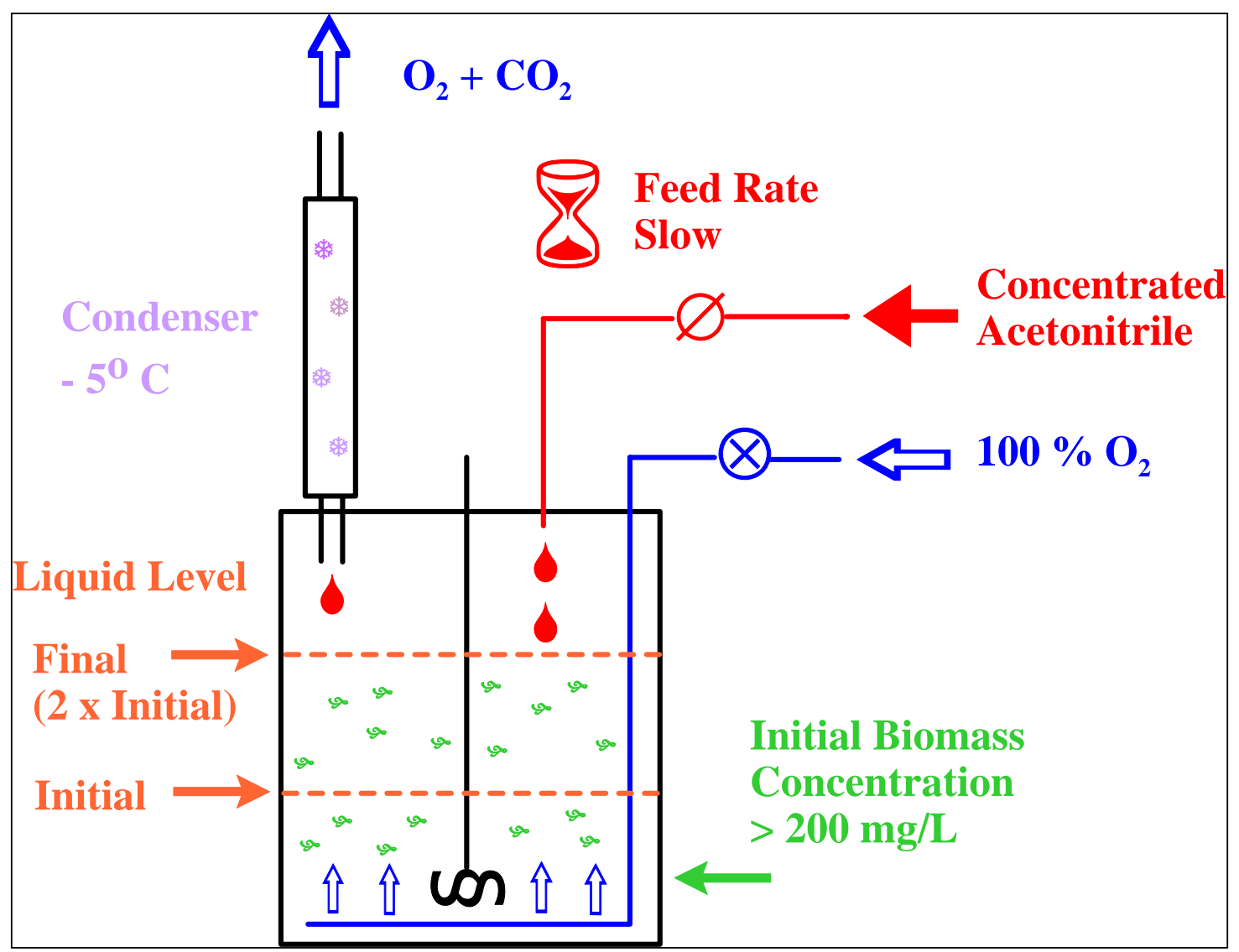


Figure 5. Sensitivity of acetonitrile biotreatment to $\mathrm{pH}$. The plot of data from Day 34 through Day 75, indicating the $\mathrm{pH}$ sensitivity of acetonitrile biodegradation. Loss of biodegradation activity was recovered by adjusting the $\mathrm{pH}$ in the drip-feed reactor to below 7.2

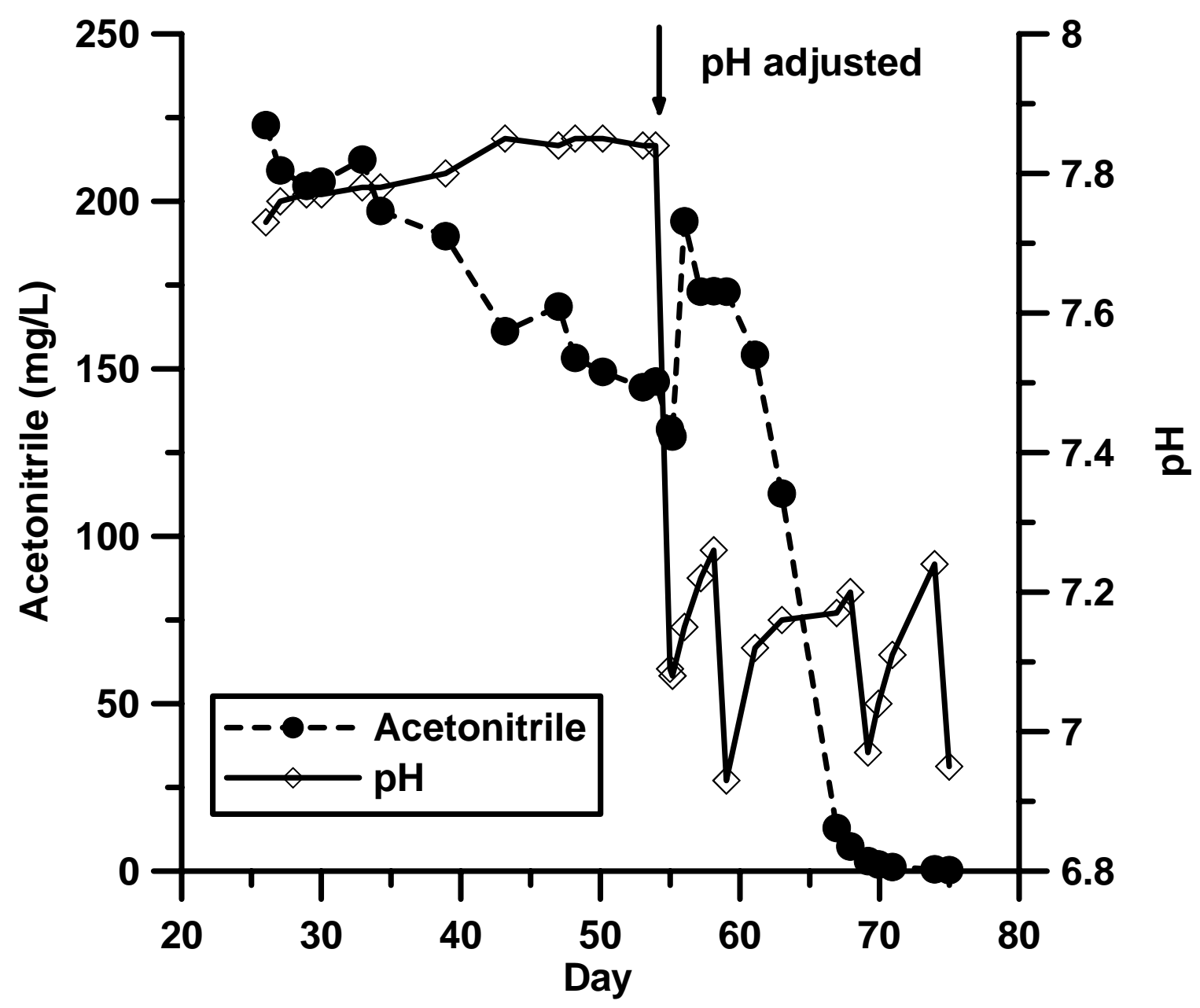


Figure 6: Acetonitrile biotreatment as a function of $\mathrm{pH}$. Normalized biodegradation rate plotted against $\mathrm{pH}$ shows that degradation rate is inhibited above pH 7.2. Drip-feed bioreactor pH is maintained between 6.2 and 7.2 for optimal performance.

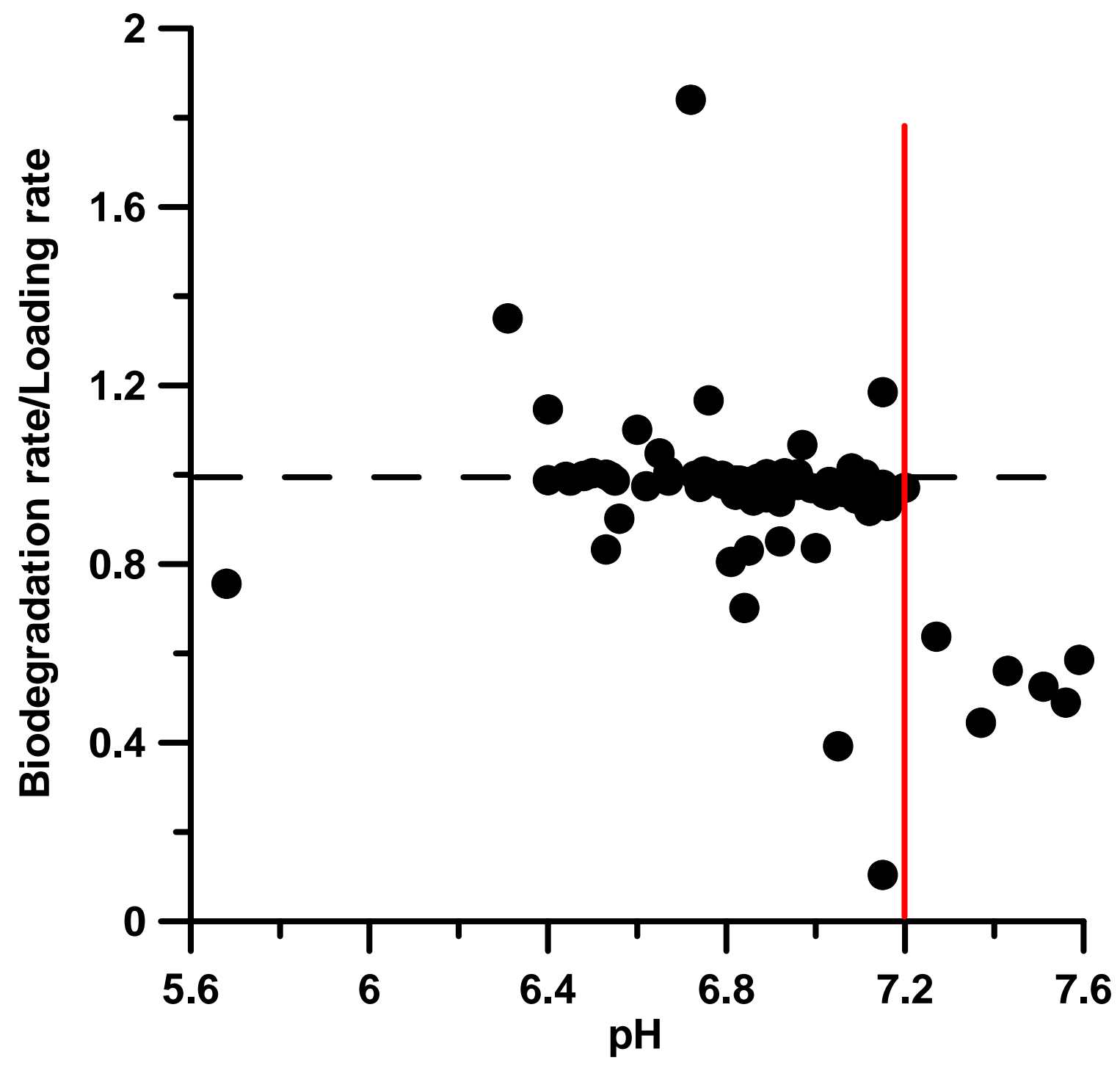


FIGURE 7. Actual and theoretical acetonitrile concentrations in the reactor. The actual acetonitrile concentration values with respect to the theoretical values indicate a treatment efficiency of $99.999 \%$, comparable to competing technologies, including incineration.

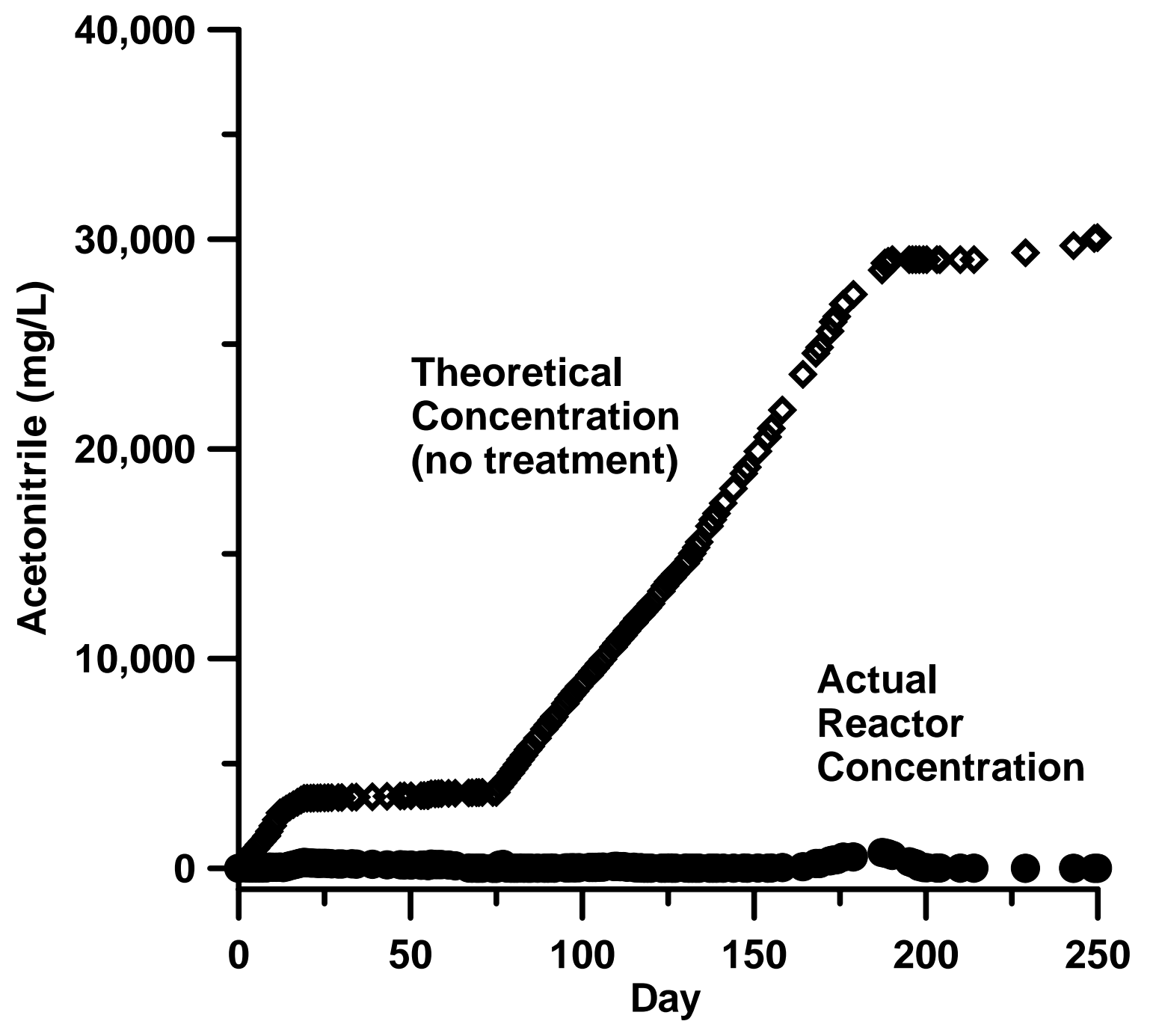


Figure 8: Drip-feed bioreactor load performance. Drip-feed bioreactor performance can be described using standard approaches. Biotreatment rate is proportional to acetonitrile loading at rates as high as $500 \mu$ g acetonitrile (mgbiomass day $)^{-1}$. Data plotted for $\mathrm{pH}<7.2$ data only.

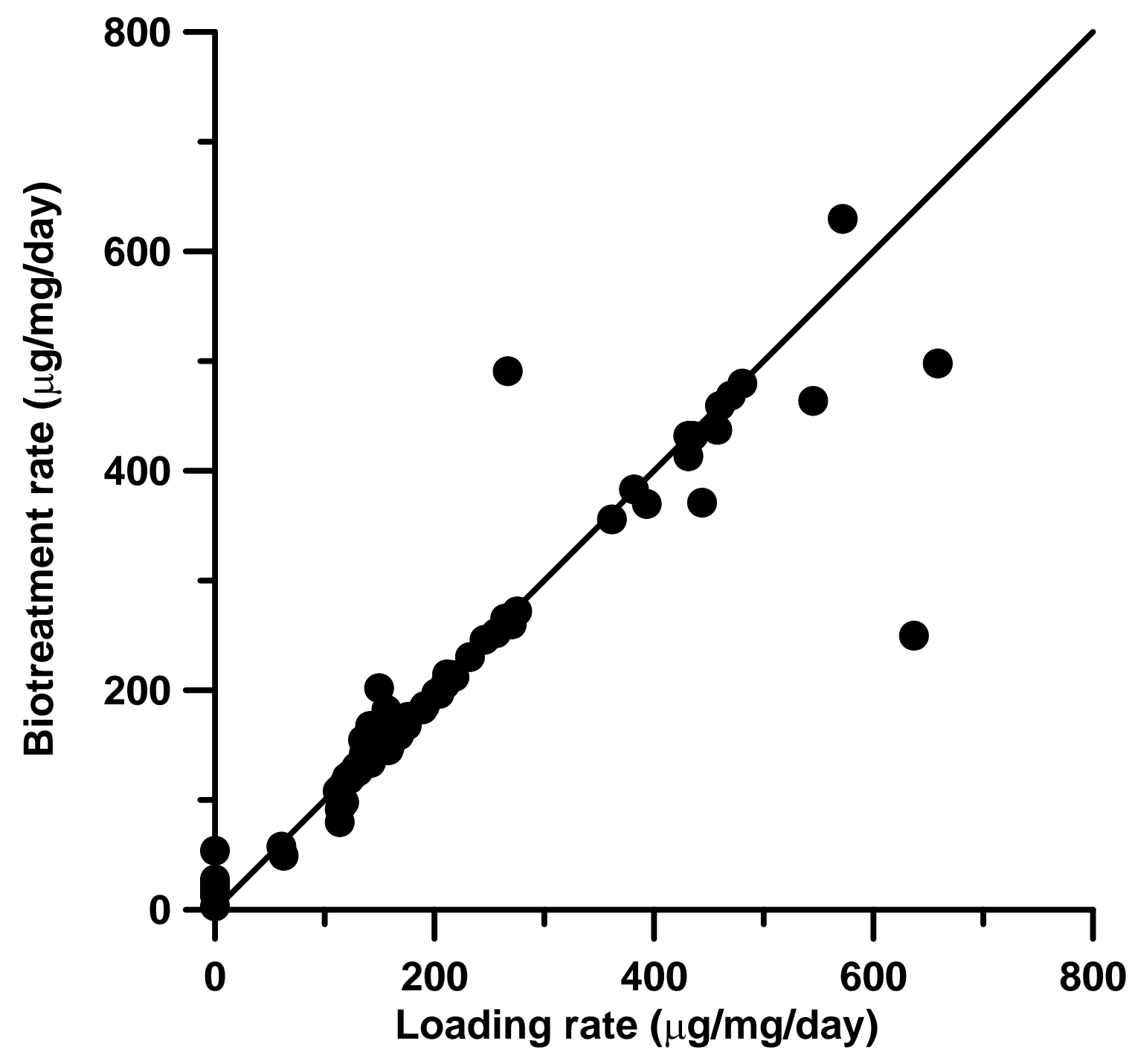


Figure 9: Drip-feed bioreactor treatment efficiency. Treatment efficiency declines at higher loading rates, indicating acetonitrile concentration will increase over time in the bioreactor at loading rates above $500 \mu \mathrm{g}$ acetonitrile (mg-biomass day) ${ }^{-1}$.

Data plotted for $\mathrm{pH}<7.2$ data only. Line represent polynomial fit to data.

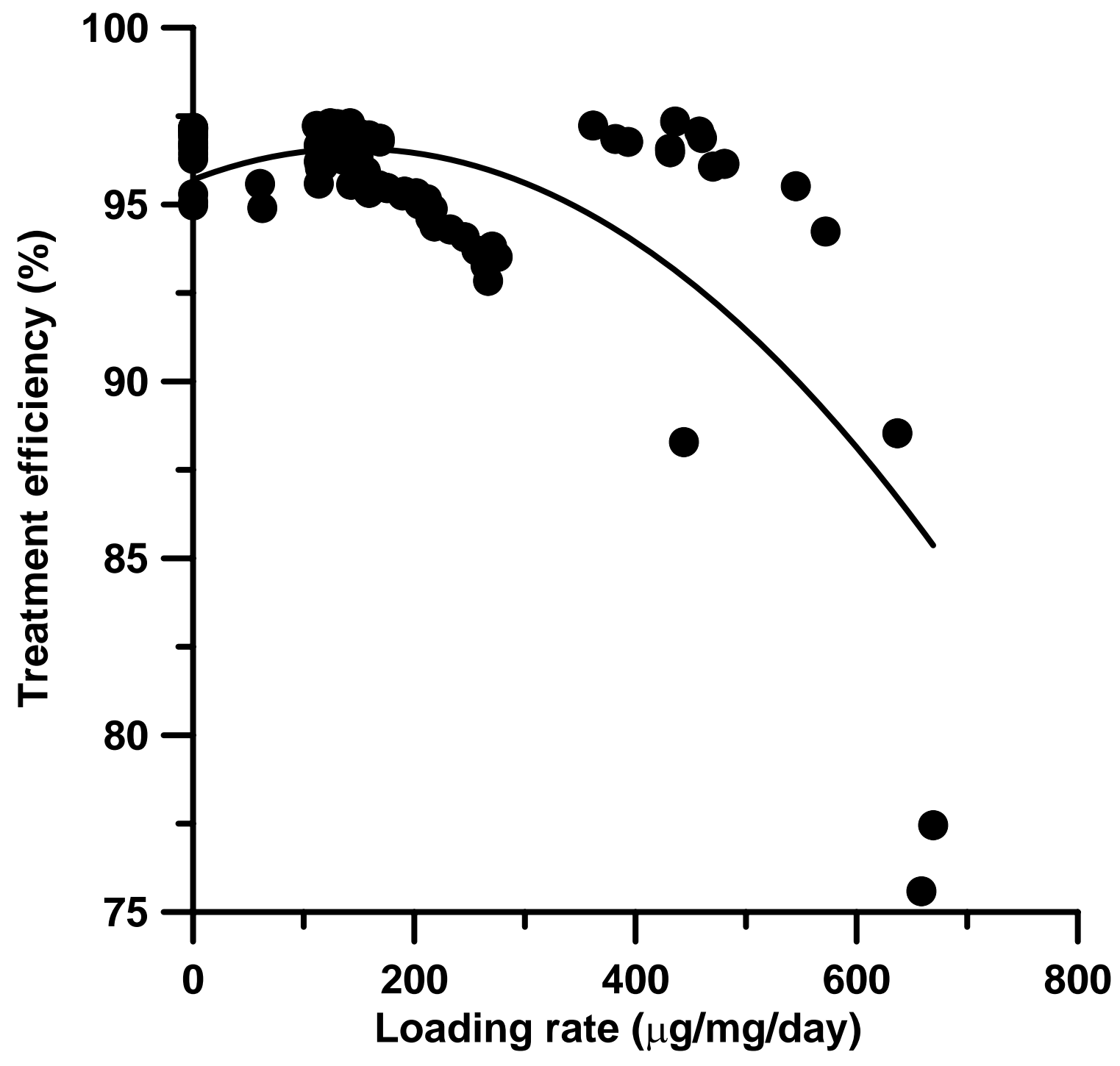


Figure 10: Biokinetic of bacteria growth in a drip-feed bioreactor. Biomass production can be described using a simple mass balance model (eq. 3, line in figure). Values of $Y$ and $k_{d}$ are from minimal sun-of-squares fit to growth model (eq. 3).

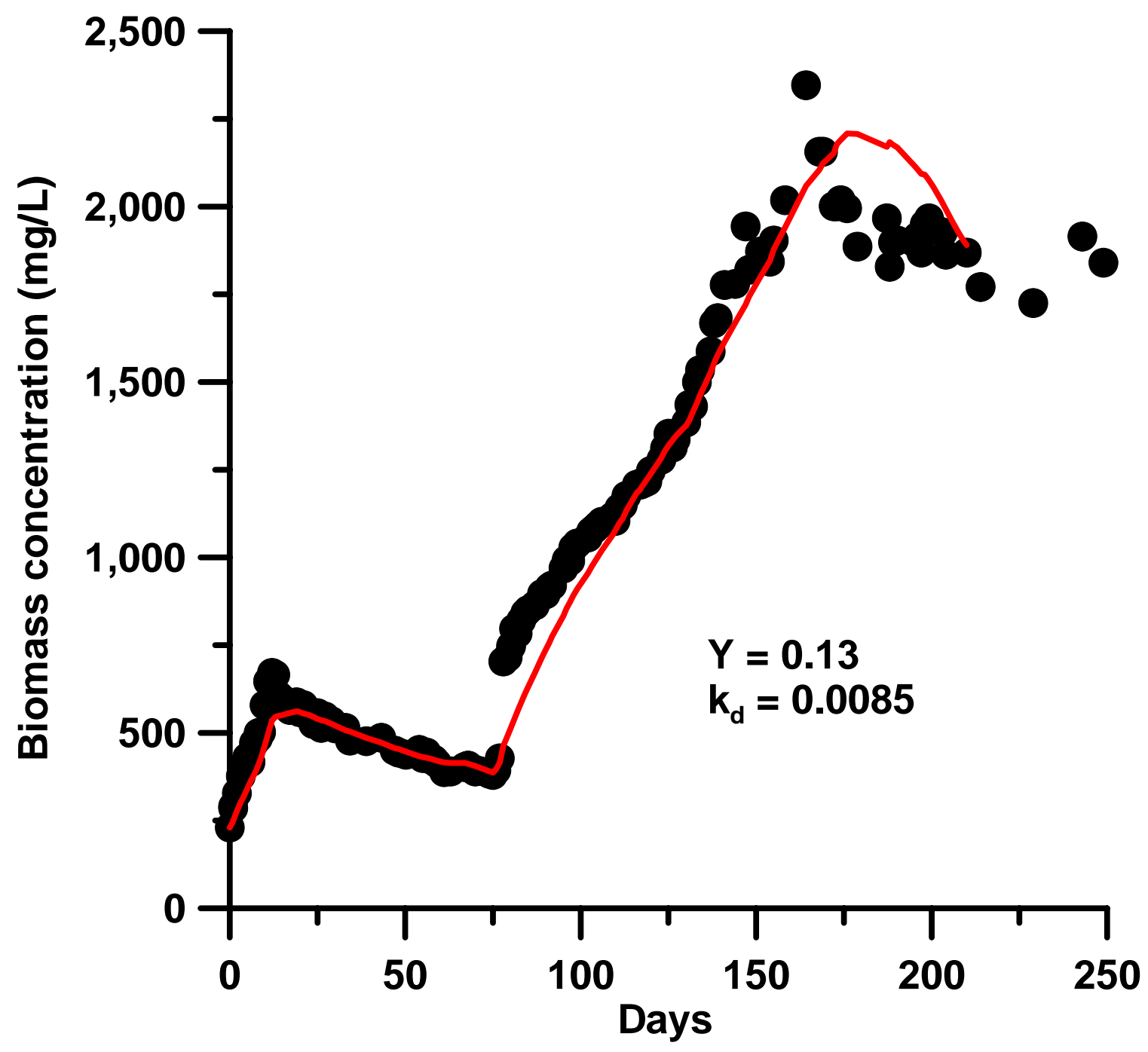

